\title{
UNA FORMA PRECAPITALISTA DE VENDA DE LA FORÇA DE TREBALL: L'AFERMAMENT DE SOLDADA; ELX, 1474-1507.
}

\section{Artur GIL I FERNANDEZ}

Tot i el domini al camp del propietari-treballador -la família és bàsicament la força de treball-, per causa d'una preponderant petita propietat agrícola (1) en mans dels cristians de la vila (2), hi ha propietaris de terra en gran, d'obradors i d'indústries amb certa empenta i abast -almàsseres, saboneries-, mercaders, notaris i altra gent que fa ofici del dret i l'escriptura, clergues i alguns cavallers -minsos-, que fan ús de mà d'obra aliena, al camp, a casa i a l'obrador.

A banda els esclaus, de mínima presència a la vila -n'hem conegut tretze al període-, i només excepcionalment remunerats pel seu treball (3), de treballadors contractats per fer-ne ús de la seva força de treball en canvis d'alguna forma de salari, en raó de la permanència temporal al servei d'un amo i dels trets que caracteritzen les relacions entre ambdues parts -graus de llibertat, forma de pagament del salari-, hem esbrinat diverses categories. «Criat» sembla condició derivada de contracte de llarga durada o permanent, fadrí o casat el treballador, al servei -polivalent: al camp, a l'obrador, com a agent comercial (4)-, exclussiu d'un amo; el «mosso», susceptible d'ésser llogat a tercera persona (5), a penes es diferencia de l'anterior, encara que podem sospitar la característica general de fadrí; la seva situació en relació amb l'amo potser es podria identificar com a jornaler permanent (6). L'escorcoll no ens ha reportat cap contracte que pogués fer més llum, i així poc hem trobat cap ordinació del Consell a ells referida quant a taxes salarials, forma de pagament, etc. Força diferent es mostra l'actuació del poder públic municipal respecte a la tercera categoria de treballadors, els bracers -de vegades també dits «obrers»-, treballadors a lloguer temporal, el tipus més semblant al proletari del sistema capitalista, venedor diàriament de la seva força de treball per un salari; tot $i$ la manca de dades quantitatives, pensem que devia ser la més abundosa de les formes d'utilització de mà d'obra aliena, sobretot en certs moments de feines estacionals, com ara magençar, segar o veremar. El Consell es mostra protector del grup dominant: assenyala l'hora de començar el treball, controlada pel rellotge i les campanes de Santa Maria, i limita els salaris, tot imposant penes als contraventors (7). 
Finalment, les formes de treball que són ara objecte d'estudi, presentades pels notaris sota un mateix títol: l'afermament de soldada, que barreja trets força propers a l'esclavitud -submissió de l'afermat-, amb altres de caire capitalista -lliure contractació, acord respecte a durada i salari-; generalment els pares o el tutor d'un noi o noia de poca edat posen aquest al servei d'algú, rebent en pagament diners i diversos béns i, de vegades, coneixements de l'ofici del patró.

Hi ha dues menes d'afermament, segons el servei i el pagament, tot i que la tipología documental sigui la mateixa i també idèntic el títol que els notaris solen afegir al marge: 1) El servei domèstic o servitud, pel qual el servidor-contractat haurà de treballar a casa $i$, de vegades, al camp, i fer tot allò que li sigui manat; la fòrmula corrent és "fer los manaments de aquells, de nit e de dia, aquells que bons e honests sien..."; i 2) el contracte d'aprenentatge: aquí serà obligació del patró ensenyar el seu ofici a qui sigui servidor-aprenent.

La problemàtica existència de l'Arxiu Municipal d'Elx -venda, foc, aiguats-, ens ha privat, en haver-se perdut part dels protocols notarials, de conèixer l'abast quantitatiu dels afermaments; per a tot el període només hem esbrinat trenta-dos contractes -vint-i-quatre de servitud i vuit d'aprenentatge-, ampliats per recerca indirecta a quaranta-tres a través d'una obligació d'assolir poder del tutor d'una minyona de Montealegre del Castillo per a afermar-la, quan ja és a casa de l'amo (8), àpoques, reconeixements de deute, donacions, nomenaments de procuradors per recabar les soldades degudes o fer tornar una criada fugida (9)...; en no saber si va reeixir, no afegim l'intent del notari Johan Martínez nomenant el batxiller Francesch de Sent Pere per a afermar "huna mossa que a de estar ab ell per lo temps que més porà e per lo preu de menys porà..." (10).

\section{La servitud}

Acompleix la servitud dos objectius complementaris: per la part contractat-servidor i per al patró. D'un costat, els pares -o tutors-, s'alliberen de la cura dels fills -vestir, calçar, alimentar, educar (11), tenir-los sans i malalts, obligacions ara del patró-, durant gairebé tot el temps en què depenen de les persones majors; a més, en arribar a edat matrimonial, rebran un mínim precís per a iniciar el seu camí independent -aixovar o terra i alguns sous-. Fora de tres casos en què ens és desconeguda -en un d'ells, l'afermada, traspassada per l'honrat Johan Tarí al seu cunyat, Francesch Torres, és, sens dubte, major (12)-, en tota la resta l'edat ens reporta el molt primerenc començar a treballar de minyons, el major dels quals només té catorze anys; la majoria és entre sis i deu i trobem el súmmum en un noi de Monfort de cinc anys (13) i una nena de quatre, tot i que va ésser cancel lat el contracte d'aquesta darrera, potser davant la previsió de la possible propera mort (14), quan tan sols havien passat tres mesos, essent la durada inicialment de catorze anys, posat que hi havia una clàusula en virtut de la qual, si dins els primers tres anys moria la nena, res no podria demanar de soldada la mare, $i$, si després, allò que fos de justícia. L'examen de les edats ens reporta una mitjana de 9,2 anys, cobrint unes extremes de quatre i catorze. 
Pel que es refereix a la durada -un màxim de setze anys per a un noi de cinc, i un mínim de dos que ha de servir un altre de tretze-, la mitjana és de 8,4, observant-ne una relació inversa edat-durada: el servei acaba en el moment en què el servidor ha assolit una edat -entre setze i vint-, adient per a fer matrimoni.

Afegint-hi que per raó del sexe trobem una majoria aclaparadora de femelles $-76,7$ \%-, la conclusió incontestable és que el problema a solucionar són, sobretot, les donzelles i el seu dot. La forma de pagament ens recolza: en onze dels divuit casos de noies afermades que coneixem com es va fer, una part -la meitat, generalment-, és lliurada en roba, joies i estris de casa i la resta en diners; tres van rebre tota la paga en roba i eines; per d'altres tres serveis, els pares o tutor reben a l'acte del contracte part del sou en béns dels que es beneficien de continent, satisfent una urgent necessitat que no pot ésser coberta més que amb la venda de la força de treball d'una filla (15). Només un cop la soldada es va pagar exclusivament en diners comptants. Argument afavoridor és que quasi totes les noies -vint de vint-i-tres-, 86,95\%-, són afermades pels seus pares; només hi ha dues òrfenes, atorgant-hi els contractes els seus tutors -un d'ells, el carnisser Francesch Pérez, nomenat pel Justícia (16); l'altre correspon a una minyona castellana (17)-; el darrer cas de les afermades per persones diferents dels pares representa només la conveniència de Joan Tarí, qui ha gaudit dels serveis de Maria Sandoval i, en traspassar-la al seu cunyat, rep dos ducats, part de la soldada (18).

Quant als servidors masculins -23,3\%-, trobem una menor disposició dels pares a afermar-los, posat que a casa $\mathrm{i}$ terra pròpies podrien fer un treball que, d'altra manera, hauria de ser substituït per un servidor-contractat, un mosso i/o peons o bracers, pagant la corresponent soldada o salari. Dels set contractes reportats per l'escorcoll, només en són responsables els pares de tres -un bracer illicità, i dos més, de professió desconeguda, habitants a Crevillent i Monfort (19)-; els quatre afermats pels tutors -parents en tres casos-, responen, pensem, a la impossibilitat de fer-se'n càrrec personalment del manteniment i educació dels seus tutelats i de posar-los en condicions de desenvolupar-se per ells mateixos (20).

El servei dels minyons sembla ésser sempre ambivalent, tot i que només un contracte ens ho revela: a més del servei a casa, és clar que poden ser utilitzats al camp (21).

La forma de pagament varia qualitativament respecte a les noies: quatre servidors reben una part en terra -en lloc de roba i eines de casa-, i la resta en diners comptants, que en un cas poden ésser canviats per un mascle (22); l'objectiu és clar: dotar d'uns mínims béns de producció, que el pare no pot lliurar. Només se'n surten d'aquesta modalitat un servei de tan sols dos anys pagat en metàllic (23) i un altre on el pare del servidor es considera ben pagat amb el tenir, vestir i calçar del seu fill, prometent no demanar "soldada nenguna" per sis anys de servei (24).

La poca edat justifica plenament la fugida dels nois, allunyats dels pares i sotmesos a explotació per persones estranyes. Per això la clàusula comú d'obligació dels pares de tornar-los, si se'n van, i retre qualsevol objecte que hagin pogut emportar-se; com a garantia, molt sovint obliguen els seus béns. Només un cop és contemplada la 
possibilitat de cancellació amistosa en cas de no ésser contentes ambdues parts (25). Emperò, coneixem de fugides (26) i trencaments, quan un cor tou ha obligat els pares finalment a recobrar els seus fills (27).

Per la part dels patrons, es tracta de gaudir durant força temps d'un servei fidel abastant totes les feines a casa $i$, molt sovint, al camp, per un preu molt modest -mitjana de 50 sous/any-. Nogensmenys, de vegades no són gaire diligents a l'hora del pagament i els pares es veuen obligats a fer demanda de la soldada (28).

L'anàlisi sociològica es veu entrebancada per la descurança d'alguns notaris, ometent dades tan significatives com ara la professió, sobretot pel que toca als pares dels afermats. Nogensmenys, podem afirmar que la servitud no és recurs econòmic reservat als miserables o als estrats inferiors de la societat urbana i rural; diferentment a València, cap cas hem conegut de noi afermat pel pare d'orfes (29). És un instrument de què es fa ús, particularment quant a les noies -pel cercar un complement dotal-, fins i tot per eminents individus de l'oligarquia, com ara Alfons d'Alvado (30).

Per la part dels patrons, el gràfic mostra la posició dominant dels «honrats»; hi són, sota aquest títol tant mercaders com una munió de menestrals: botiguers, sastres, un calceter, un apotecari, un barber, un pintor i un mestre de cases; altres dos són un cavaller -força escassos a la vila-, i un llaurador, romanent desconeguts més del $50 \%$.

Un darrer aspecte a considerar és la mobilitat geogràfica dels servidors, que almenys aparentment revela una posició favorable a la vila illicitana: front a dos servidors desplaçats a Alacant (31), notem catorze forans al servei de famílies il licitanes $-32 ' 55 \%$ dels afermats-; sens menysprear les condicions del mercat, la proximitat geogràfica potser sigui explicació de la presència d'individus de Guardamar, Oriola, Almoradí, Crevillent, Monfort i Cox (32); els vinguts de Biar, Xixona i Onil (33) es poden relacionar amb els contactes derivats del pasturatge al camp d'Elx de ramats de les terres interiors; les relacions mercantívoles amb Villena i amb Castella -importació de blat, exportació de sabó, sovintejant la presència de carreters castellans-, semblen al darrere de la servitud de noies procedents d'El Provencio i Montealegre (34).

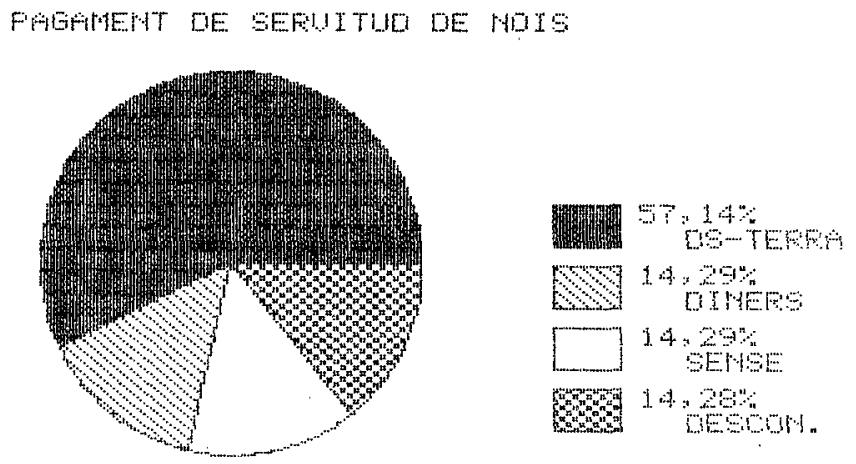



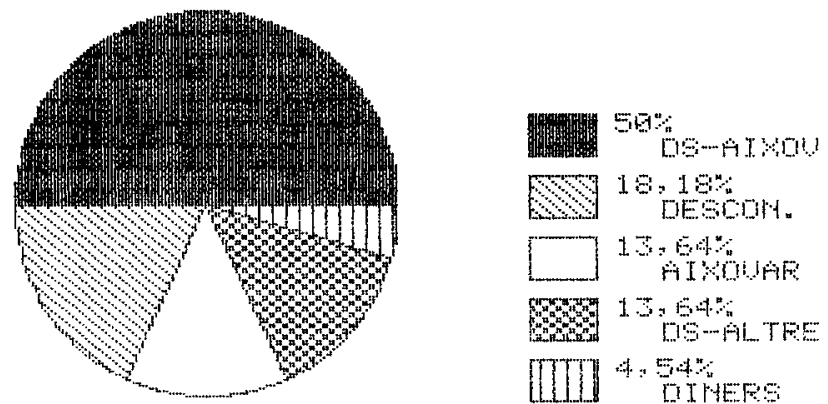

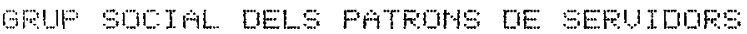
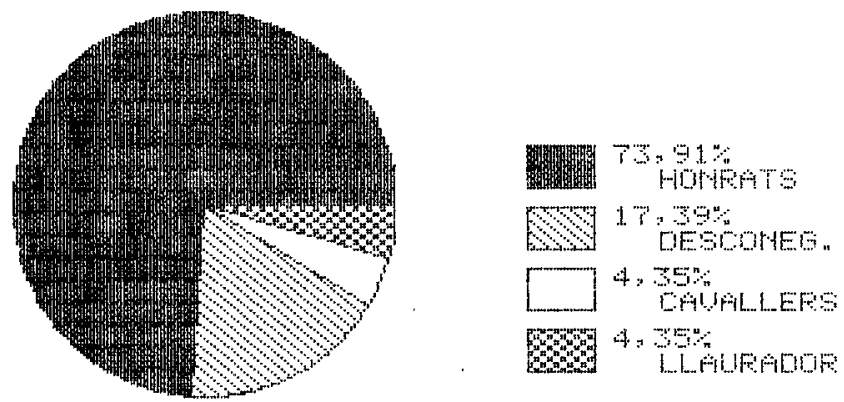

\section{El contracte d'aprenentatge}

Per la part de l'aprenent és ben palès l'objectiu de l'afermament per l'aprenentatge: aprendre l'ofici del mestre-patró, que aquest haurà d'ensenyar-li, a més de donar-li aliment $i$ vestir-lo. La compensació serà fer tots els manaments del patró i servir-lo, doblement, a l'obrador i a casa, exceptat un cas dels que hem pogut estudiar -una persona gran-, que sembla fer feina només a l'obrador (35). Com observa Beneyto a la València del XVI, l'aprenent es troba front al mestre en una situació domèstica, essent així classificat pels furs (36).

Si l'aprenentatge professional té com a consequiència la servitud, l'agermanament d'ambdós vessants també es mostra inversament: en certs casos, l'ineluctable recurs a la submissió del servei domèstic -orfandat, misèria que obliga a lliurar un fill per ser afillat-, no és inconvenient per demanar un mínim nivell d'illustració i el mestratge en un ofici, suposades les facultats de l'afermat (37).

Els servidors, però, a les acaballes del contracte rebran alguns diners i un troç de terra -els nois-, o aixovar de casa $i$ algunes joies -les noies-; per als aprenents, llevat d'un cas -l'excepció esmentada, on l'aspirant a oficial signa un contracte de tipus capitalista, tot ajustant un salari en metàllic a cobrar per mesos-, el pagament del servei no existeix realment. Hom accepta com a paga bastant rebre els coneixements de l'ofici i ésser alimentat i vestit; fins i tot, l'escorcoll ens ha mostrat el cas d'un mestre velluter, 
Jaume Romero, qui ha cobrat certa quantitat del pare de l'aprenent (38). Més aviat com a element d'aparença que no pas com a salari ha d'ésser tinguda la vestidura, adient a la nova categoria professional, que rep de vegades l'aprenent en acabar el contracte (39). En el cas dels barbers - «barbers i cirurgians»-, aquest darrer complement es mostra força ajustat per iniciar l'exercici professional: un estoig contenint els instruments adients, "com se acostuma a donar als aprentissos del dit ofici" (40).

Així com en la servitud, aquí també és una condició normal que el pare hagi de tornar el fadrí, si aquest se'n va de l'amo, perdent el temps passat de servitud i aprenentatge i començant de bell nou (41); o podrà el mestre contractar un altre aprenent, a despesa del pare del primer; també hi és la compensació inversa: si el mestre no vol ensenyar l'ofici -fins $i$ tot hi ha de concrecions tècniques-, el pare podrà posar el fill aprenent amb un altre mestre, a despesa del primer (42).

Diversament a com succeeix en la servitud, no hi trobem cap aprenent afermat per tutor. Sempre són els pares qui signen el contracte, llevat de tres aprenents, atorgants ells mateixos dels seus contractes (43).

Minses poden ser les conclusions derivades de les dades quantitatives; són escassos -deu- els contractes d'aprenentatge que directament o indirecta hem pogut esbrinar. Així, no és possible d'establir una durada mitjana del període d'aprenentatge; també ens és negada qualsevol mena d'informació quant a examens o matrícules per a oficial o mestre. Potser, malgrat les afirmacions d'Ibarra i Ramos Folquès respecte a antigues ordinacions gremials (44), no n'hi havia; l'acord entre les parts segons conveniència, dificultat de l'ofici, concurrència de mestres, són qui determinen els termes dels contractes, on -mai ho hem d'oblidar-, la posició dominant és la del mestre-amo, que fins i tot en algun cas -el mestre vidrier Olit-, la fa servir per reservar-se una mena de drets de formació professional sobre l'aprenent, obligat, quan sigui oficial, a treballar per a ell a igual salari ofert per un altre mestre (45).

La dispersió professional revela una preponderància dels oficis relacionats amb el tèxtil -sis de deu contractes-, l'activitat artesanal més característica, encara que no la de major empenta -la saboneria és l'unica d'abast i vocació exportadora-. Tanmateix, tot i les pèrdues documentals i el fet de l'endotècnia (46), sembla un cens poc nodrit, que revela unes dimensions força reduïdes de l'obrador, actuant-hi un mestre $i$, només en certs casos, un aprenent, i el curt abast del tèxtil i d'altres indústries, com ara la sabateria, de què no coneixem a l'època estudiada cap afermament per l'aprenentatge.

Tot $\mathrm{i}$ les mancances i les limitacions de les xifres, pels aspectes qualitatius fem costat Cipolla (47): a la societat preindustrial, on la impossibilitat familiar de fer inversions personals -educació, formació professional, exceptats els fills de menestrals-, compelleix a l'afermament, trobem, si no amb idèntica amplitud, per la intensitat de l'explotació, un ús del treball infantil semblant a l'originat per la revolució industrial; i més encara en el cas dels aprenents: sotmesos, com els servidors, a la més estricta submissió(48), deixen d'ésser, com afirma Hilton(49), individus que volen aprendre un ofici, esdevenint treballadors sotmesos a la més intensa explotació, que no reben més que allò estrictament precís per al seu manteniment. 


\section{NOTES}

(1) Així ho palesem a la nostra tesi doctoral, "Elx a l'època de Ferran el Catòlic";Univ. d'Alacant, 1991, inèdita.

(2) Propietat plenera, lliure, llevat de les terres de "Donatiu", que fan a la senyoria un moderat cens; a part el "Magram", terra dels mudèjars.

(3) A.M.E., Ll. H/46, n 48: nota contemporània, on es diu que a l'arxiu -suposem Actes de Consell perdudes-, és registrat el juliol del 1497 com la vila pren per seu "Juanico Perpinán, esclavo que es de Antonio Perpiñán de Andrés, para que este toque en los pregones la trompeta y haga aquello por dos florines, y el Consejo le dará albergue y le alimentará."

Alguna mena de salari rep Florentina, lliberta, en passar a ser «criada» de Bertomeu d'Alvado -A.M.E., P. N. nº 80, f. 376 (1507-10-03)-

(4) A.M.E., P. N. $n^{\circ} 10$, f. 269 (1487-12-29): Ferrando de Madrit nomena procuradors seus, per a comprar bestiar llanar i cabrum, el seu fill, Joan, i Domingo de Sòria, criat seu.

(5) A.M.E., Llibre de Clavaria 1490-1500, f. 383v (1498-11-14): paga el clavari tres sous a Bertomeu d'Alvado "per dos dies que un moço de aquell feu faena ab mestre Mercado en la font".

(6) BENEYTO PÉREZ, J., "Regulación del trabajo en la Valencia del 500", Anuario de Historia del Derecho Español, vol. 7 (1930), pp. 183-310; recull la fòrmula «estar ab amo» (p. 254).

(7) RAMOS FOLQUÈS, A., "Historia de Elche", Elx, 1971, p. 114, reporta el pagament fet a Franci Campino, de Barcelona, per tres ampolletes d'hores per a fer rellotge; implantat un de mecànic, és adobat diverses vegades -A.M.E., Ll. Cl. 1490-1500, f. 23 (1490-12-06), i 28 (149103-02)-; el 1497 es va fer venir Leonardo de Toledo, "manyà i rellonjer..., per ço com estava molt desbaratat" -Ibidem, f. 255 (1497-01-17).

El 1466 decreta el Consell la crida a missa major de les campanes de Santa Maria com a senyal per sortir de la vila els bracers, sots pena de perdre el jornal, fixat en dos sous i mig per segar i tres per cavar i magençar -A.M.E., A.C., Ll. 16, f. 54v (1466-04-20)-. El 1489 és més explícit quant al començament del treball: una hora després de sortir el sol -A.M.E., A.C., Ll. 19, f. 34 (1489-03-29)-.

La diferència quantitativa amb València no fa precisa a Elx l'existència de res semblant a l'afermador de macips o «afermamoços», reportat per VICENTE VICENT CORTINA -"Los trabajadores del campo en la Valencia del siglo XV", Actes IV C.H.C.A., vol. II, pp. 100-103- i MIGUEL LLOP -"Un aspecto económico de la Valencia del siglo XVI: Los salarios", pp. 133-137-, i funció ben explícita en l'Estatut del Treball agrícola de 1555, referenciat per Joan Beneyto Pérez art. citat, p. 293-: “... entenga en afermar los mosos y donar amos a daquells conforme a les faenes que sabran fer..."

(8) A.M.E., P. N. n 10, f. 162v (1487-03-07).

(9) A.M.E., P. N. no 4, f. 34 (1474-09-03).

(10) A.M.E., P. N. nº 80, f. 349 (1507-08-26).

(11) A.M.E., P.N. n9 9, f. 72 (1480-05-24): hi és el molt expressiu "governar".

(12) A.M.E., P. N. no 80, f. 207-208v (1506-06-16).

(13) A.M.E., P. N. n²9, f. 65 (1480-05-08). 

13.

(15) A.M.E., P. N. n 9, f. 206v (1481-04-25): Galcerà Togores, apotecari d'Oriola, habitant a Elx, lliura a Johan de Cardona un ase, per un valor de cent sous, la meitat del preu de la servitud per sis anys de Joana, filla de Cardona, d'edat de deu anys; al P. N. $n^{\circ} 10$, f. 182-183, trobem el 10 de juny del $1487 \mathrm{com}$ Bernat Stheve, de Biar, per afermar sa filla amb Anthoni Castell, d'Elx, rep civada per valor de 10 sous (apr. un cafís), com a part dels 310 en què és fixat el preu de set anys de servei. Finalment, -Ibidem, f. 162v-, el carreter de Montealegre del Castillo Pero Sánchez, qui s'obliga a assolir poder del tutor de Catalina, filla de Joan Martín, ja mort, afermada amb el mercader d'Elx Benito Núnyez, ha rebut, com a part de la soldada, 12 quintars de figa, a preu de 6 sous i 3 diners el quintar -total, doncs, 75 sous-.

(16) A.M.E., P. N. no 9 , f. 94-95 (1480-07-22).

(17) Vid. nota 14.

(18) Vid. nota 11.

(19) A.M.E., P. N. $n^{2} 10$, f. $23 v-24$ (1486-02-06), $n^{\circ} 80$, f. 23 v (1506-07-21) i nº 9, f. 65 (1480-05-08).

(20) El més destacat potser sigui el de Pere Javaloyes, qui, com a tutor dels fills i béns del seu germà Jaume, aferma Berthomeu, nebot, de 7 anys, l'octubre de $1480-P$. N. nº 9, f. 135v-136-; i el vint de desembre del mateix any l'altre nebot, Jaume, de deu anys -P. N. n⿳9 9, f. 165v-166-.

(21) A.M.E., P. N. n 9, f. 135v-136 (1480-10-01): Bertomeu Javaloyes haurà de fer "tots els manaments a la art de la llauró o altres qualsevol".

(22) A.M.E., P. N. n² 9, f.135v-136 (1480-10-01).

(23) A.M.E., P. N. nº 10, f. 23v-24 (1486-02-06).

(24) A.M.E., P. N. $n^{\circ} 80$, f. $231 v$ (1506-07-21).

(25) A.M.E., P. N. nº 10, f.182- 183 (1487-06-10).

(26) A.M.E., P. N. n" 4, f. 34 (1474-09-03): Maria "La Viscahïna", d'Alacant, nomena com a procurador el notari Johan de Bonavida, per "demanar devant qualsevol jutge huna criada sua, la qual ella té afermada a soldada, e se li és fogida..."

(27) A.M.E., P. N. nº 12, f. 166 (1499-03-06).

(28) Així, l'honrada Catalina, esposa en terceres núpcies de Ginés Porta, d'Almoradí, nomena Jaumot Sarrió procurador per tal de demanar del pintor Pere Oliver la soldada dels quatre anys que l'ha servit la seva filla -P. N. $\mathrm{n}^{\circ}$ 80, f. 232v (1506-07-30)-. Diferent és la causa de la reclamació feta pel mateix Sarrió, com a procurador de sa mare, de la soldada de les seves germana i filla, als hereus de Jaume Javaloyes -P. N. no 12, f. 188 (1499-07-25)-: en morir el dit Javaloyes, no va cobrar i va haver d'esperar el pagament dels fills, Berthomeu i Jaumot, els quals també havien estat afermats pel seu oncle i tutor, Pere Javaloyes -P. N. n² 9, f. 135v-136 if. 165v-166-.

(29) BENEYTO PÉREZ, J., art. citat, p. 264.

(30) A.M.E., P.N. n 12, f. 3v (1497-02-03): Miquel Manressa s'obliga a pagar 95 sous a Alfons d'Alvado, per deute de la soldada d'una filla d'Alvado "qui stava ab seu germà".

(31) A.M.E., P.N. n² 9, f. 61v (1480-04-20): el patró és de la famúlia Ferrández de Mesa; i P.N. nำ 9 , f. 72 (1480-05-24).

(32) A.M.E., P.N. nº 5, f. 28 (1480-05-06), nº 9, f. $81 v(1480-06-18)$, f. 54 (1480-04-12) i f. 65 (1480-05-08); n 80, f. 231v (1506-07-21) i f. 232v (1506-07-30).

(33) A.M.E., P.N. $n^{2} 10$, f. 182 (1487-06-0), n² 12, f. 122v (1498-09-23) if. 166 (1499-03$06) ; n^{\circ} 80$, f. 5 (1504-01-09) i f. 178 (1506-03-12).

(34) A.M.E., P.N. nº 12, f. 176 (1499-05-12) i n⿳⺈ 80, f. 207 (1506-06-10).

(35) A.M.E., P. N. $n^{\circ} 80$, f. 249v (1506-11-25): el contractat-aprenent signa per ell mateix un 
contracte de tipus capitalista amb el sastre Alfonso Portes; rebrà pel servei cent sous, a raó de vuit sous i quatre diners cada mes.

(36) BENEYTO PÉREZ, J., art. cit., p. 224.

(37) La mare de Joanot Vives, fill orfe de l'argenter Pere Vives, d'Alacant, aferma aquell amb Aldonça, vídua del mercader illicità Antoni Queixans, per a servir-la durant any i mig, en què haurà de mantenir-lo i "mostrar-li llegir e scriure", i després portar-lo a València "e fer-li mostrar a ofici de teixidor de seda o argenter 0 altres oficis bons" -A.M.E., P.N. $\mathrm{n}^{\mathrm{N}}$ 9, f. 219v-220 (1481-0601)-.

Quan l'espaser d'Alacant Ginés Ximeneç demana a l'humil moliner d'Elx Joan Domingues un fill, Joan, per a afillar-lo, Domingues "entén que lo dit Johanet valrà més e aprenga oficial", a més de "fer-li totes les obres que pare e mare deuen fer a fill, demostrant-li son ofici" -lbidem, $f$. $159 \mathrm{v}(1480-12-01)-$.

(38) A.M.E., P.N. $n^{\circ} 80$, f. 83 (1504-10-10).

(39) A.M.E., P. N. n 9, f. 187v (1483-03-01): a Fernando de Castro Xuriç el sastre Pere Amorós, a la fi dels tres anys de contracte, haurà de "fer-li capa e jupó de fustam e calces e çabates e camisa e un gonell, tot de nou..."; Perot Portes ha d'ésser vestit "rahonablement de nou de drap de huytè tot complidament" per Perot Tristany, abaixador -P. N. nº 12, f. 34 (1497-08-09)-.

(40) A.M.E., P. N. nº 80, f. 129 (1505-07-01).

(41) A.M.E., P. N. $n^{\circ} 9$, f. 187v (1481-03-01).

(42) A.M.E., P. N. $n^{\circ}$ 10, f. 181v-182 (1487-06-07): el mestre velluter Gonçalbo Rodríguez Alulayes ha d'ensenyar a LLuïsot Terrades, fill del calceter Daniel Terrades, "texir vellut doble e senar, e cetí doble e senar..."; si Lluís se'n va, Alulayes podrà portar "hun lavorant, a messió e despessa del dit en Daniel Terrades"; i si el mestre velluter no vol ensenyar-li, "que lo dit en Daniel Terrades, en fi del temps lo puxa metre ab un mestre li mostre lo dit ofici, a messió e despessa del dit Aluleix".

(43) A.M.E., P. N. nº 80, f. 129 (1505-07-01), nº 80, f. 249v (1506-11-25); i nº 9, f. 187 (1481-03-01).

(44) IBARRA I RUIZ, P., "Elig, noticia de algunas instituciones y costumbres de la Edad Media" -Actes III C.H.C.A. (València, juliol, 1923)-; València, 1928, p. 23.

Ramos Folquès a "La industria, el comercio y la agricultura en Elche"; Elx, 1973, passim, reporta per a diversos gremis les ordinacions del 1589.

(45) A.M.E., P.N. n 5, f. 5v (1480-01-23); Miquel Navarro, aprenent vingut de Planes, s'obliga a no deixar Joan d'Olit, passats els tres anys d'aprenentatge, per un altre vidrier, essent el salari igual.

(46) Reproducció dins l'àmbit familiar dels coneixements dels oficis, concepte encunyat per D. WORONOFF -'Les ouvriers de la sidérulgie ancienne en France", p. 114-, i que té en compte FERNANDO DÍEZ RODRÍGUEZ a "Viles y mecánicos. Trabajo y sociedad en la Valencia preindustrial"; València, 1990, p. 29.

(47) CIPOLLA, C. M., "Historia económica de la Europa preinđustrial", Madrid, 1976, pp. 81 i 102 .

(48) HEERS, J., "Esclavos y sirvientes en las sociedades mediterráneas durante la Edad Media"; València, 1989, pp. 144 i ss.; exposades les limitacions de la llibertat personal, mostra no obstant certa confusió entre servei lliurement contractat i l'estat de captivitat per deutes de musulmans.

(49) HILTON, R., "La transición del feudalismo al capitalismo"; Madrid, 1980, p. 26.f. 249v ( 506-11-25): el contractat-aprenent signa per ell mateix un contracte de tipus capitalista amb el sastre Alfonso Portes; rebrà pel servei cent sous, a raó de vuit sous i quatre diners cada mes. 